\title{
Ontogenia do fruto em desenvolvimento de Alternanthera tenella Colla e Amaranthus blitum Linnaeus (Amaranthaceae)
}

\author{
Vanessa de Carvalho Harthman ${ }^{1,2}$ e Luiz Antonio de Souza ${ }^{1}$
}

Recebido em 1/09/2011. Aceito em 24/05/2012

\begin{abstract}
RESUMO
(Ontogenia do fruto em desenvolvimento de Alternanthera tenella Colla e Amaranthus blitum Linnaeus (Amaranthaceae)). Alternanthera tenella Colla e Amaranthus blitum Linnaeus são espécies invasoras que ocorrem em culturas e terrenos baldios na região de Maringá, Paraná. O trabalho teve por objetivo a análise morfoanatômica dos frutos em desenvolvimento e estruturas não pericárpicas dessas duas espécies, com a finalidade de contribuir com informações estruturais para identificação das espécies, classificação dos frutos e investigações ecológicas. Flores e frutos foram coletados no campus da Universidade Estadual de Maringá, fixados em Glutaraldeído, secionados em micrótomo de rotação e corados com a azul de Toluidina. As bractéolas e perigônio são persistentes nos frutos e têm estrutura diferente nas duas espécies. O aquênio de Alternanthera tenella mantém o mesmo número de estratos celulares que o ovário, que sofrem colapso na fase madura, exceto o mesocarpo interno que se mantém com espessamento parietal em U e cristais. O utrículo de Amaranthus blitum é semelhante ao ovário em número de camadas celulares e apresenta aerênquima quando maduro. As sementes maduras são exotestais, com mesotesta e endotesta colapsadas, e embrião curvo. Nesse estudo, foram registrados alguns caracteres estruturais dos perigônios e dos frutos que são potencialmente significativos para caracterização e separação das espécies, ao contrário das sementes que são muito semelhantes.
\end{abstract}

Palavras-chave: aquênio, perigônio, planta invasora, utrículo

\begin{abstract}
(Ontogeny of fruits of Alternanthera tenella Colla and Amaranthus blitum Linnaeus (Amaranthaceae)). Alternanthera tenella Colla and Amaranthus blitum Linnaeus are weeds that occur in crops and uncultivated areas in the Maringá region of Paraná. In this study, a morphoanatomical analysis of fruit development and the pericarp of $A$. tenella and A. blitum was made in order to contribute structural information for species identification, fruit classification, and ecological investigations. Flowers and fruits were collected at the campus of the State University of Maringá, Paraná, fixed in glutaraldehyde, sectioned with a rotary microtome and stained with Toluidine blue. The bracteoles and perigone are persistent in the fruits and are structurally different in both species. The achene of A. tenella maintains the same number of cell layers as the ovary, and these layers collapse during the mature phase, except for the inner mesocarp, where $U$ thickened cell walls and crystals remain. The utricle of A. blitum is similar to the ovary in number of cell layers and has aerenchyma when it is ripe. Mature seeds are exotestal, with a collapsed mesotesta and endotesta, and curved embryo. In this study, some structural characters of the perigone and of the fruits were found that could potentially be used to separate the species; unlike the seeds, which were very similar.
\end{abstract}

Key word: achene, perigone, utricle, weed

\footnotetext{
${ }^{1}$ Universidade Estadual de Maringá, Centro de Ciências Biológicas, Departamento de Biologia, Maringá, PR, Brasil

${ }^{2}$ Autor para correspondência: vanessaharthman@hotmail.com
} 


\section{Introdução}

O estudo de plantas invasoras ou daninhas possui interesse botânico, ecológico e econômico. Leitão-Filho (1968) considera que é necessária a investigação dessas plantas não só sob o aspecto sistemático, mas também sobre sua biologia e relação com outras espécies. Os trabalhos relacionados aos frutos e às sementes de espécies invasoras têm se tornado fundamentais como contribuição para controle ou aproveitamento dessas plantas (Souza 2006). A morfologia de frutos e sementes tem importância particular para o conhecimento das espécies em geral; a estrutura das sementes é útil para o entendimento da filogenia das espécies, manejo, análise e produção de plantas agrícolas e florestais, como também em pesquisas relacionadas com o desenvolvimento da vegetação, com a arqueologia e com a paleobotânica (Costa Silva et al. 2003).

Amaranthaceae, que inclui Chenopodiaceae, é família de distribuição cosmopolita, não ocorrendo, entretanto, em regiões mais frias do Hemisfério Norte. Possui cerca de 170 gêneros e 2.360 espécies (Judd et al. 2002; Souza \& Lorenzi 2008), que são ornamentais, alimentícias, medicinais e invasoras. Entre estas destacam-se as espécies invasoras de Alternanthera Forssk. e Amaranthus L. (Souza \& Lorenzi 2008).

Os frutos de Amaranthaceae pertencem comumente aos tipos aquênio, utrículo ou cápsula circuncisa (pixídio) (Judd et al. 2002). Costea et al. (2001) investigaram o pericarpo de várias espécies de Amaranthus com finalidade taxonômica, sugerindo que podem ser estabelecidos padrões estruturais para identificação das espécies. Por outro lado, estes mesmos autores registraram que as diferenças anatômicas entre frutos indeiscentes e deiscentes, que ocorrem em Amaranthus, são pequenas. Outras investigações morfoanatômicas sobre frutos (pericarpo e semente) de espécies de Amaranthaceae são registradas na literatura (Pal et al. 1990; Prego et al. 1998; Shepherd et al. 2005; Oyama et al. 2010).

No estudo do pericarpo das espécies já investigadas de Amaranthaceae parece ser comum a presença de tecido esclerenquimático no pericarpo, que pode apresentar variação estrutural de suas células. Nos trabalhos de frutos de Amaranthaceae, com exceção do trabalho de Oyama et al. (2010), constata-se que não há análise das estruturas não pericárpicas que são comuns nesses frutos, e que parecem desempenhar papel importante nas funções de proteção e dispersão.

No presente trabalho foram selecionadas duas espécies invasoras de Amaranthaceae que são abundantes em culturas agrícolas e terrenos baldios, Alternanthera tenella Colla e Amaranthus blitum Linnaeus, com o objetivo de estudar a anatomia e morfologia de seus frutos e suas estruturas não pericárpicas, com a finalidade de contribuir com informações estruturais para identificação das espécies, classificação dos frutos e investigações ecológicas.

\section{Material e métodos}

A coleta do material botânico foi realizada na área urbana de Maringá, Paraná, Brasil, sob as coordenadas S 23 $24^{\prime} 13,7^{\prime \prime} \mathrm{W} 51^{\circ} 56^{\prime} 24,6^{\prime \prime}$ para Alternanthera tenella e S $23^{\circ}$ $24^{\prime} 13,0$ W 51 56'26,5' para Amaranthus blitum, e altitude média de 542m. Exsicatas desses materiais foram depositadas no Herbário da Universidade Estadual de Maringá (HUEM) sob números de registro 16501, V.C.Harthman, 119 (A. blitum) e 16503 (A. tenella), V.C.Harthman, 116.

O material botânico para estudo morfoanatômico consistiu de ramos com botões florais, flores e frutos em diferentes fases de desenvolvimento. Após a retirada do ar dos tecidos, o material foi fixado em glutaraldeído $1 \%$ em tampão fosfato 0,1 M, pH 7,2 e armazenado em álcool 70\% (Johansen 1940). O material botânico fixado foi incluído em historresina (Guerrits 1991), secionado transversal e longitudinalmente em micrótomo de rotação, corado com azul de Toluidina em tampão fosfato 0,1 M e pH 4,7 (O’Brien et al. 1964) e montado em resina sintética (permount $\mathrm{e}$ histolan) (Johansen 1940).

Foram realizados testes histoquímicos para a detecção de algumas substâncias em seções de material botânico emblocado, com floroglucina em meio alcoólico e ácido (Berlyn \& Miksche 1976), para lignina; com ácido sulfúrico (Sass 1951) e ácido clorídrico 10\% (Souza et al. 2005) para verificar cristais de oxalato cálcio e, finalmente, vapor de amônia para a presença de betalaína (Johansen 1940). O padrão de venação das bractéolas e perigônio foi analisado em material fresco diafanizado em hidróxido de sódio, segundo técnica de Foster (1950).

As ilustrações foram feitas com fotomicrografias obtidas por captura de imagem em microscópios Olympus BX50 e Leica ICC50. As escalas referentes às ilustrações foram obtidas com lâmina micrométrica nas mesmas condições ópticas utilizadas para cada caso.

A análise estrutural dos frutos e sementes em desenvolvimento foi baseada em terminologia usada por Corner (1976), Roth (1977), Spjut (1994), Paoli (2006) e Souza (2006).

\section{Resultados}

\section{Pericarpo em desenvolvimento}

Alternanthera tenella possui fruto do tipo aquênio, de superfície lisa, glabra, de coloração marrom, enquanto Amaranthus blitum apresenta fruto do tipo utrículo com superfície granulosa e também de cor marrom. Ambas as espécies apresentam estruturas não pericárpicas persistentes, como as bractéolas e o perigônio.

As bractéolas de ambas as espécies diferem pelo tamanho e tipos de tricomas. Em A. tenella, as bractéolas são maiores e apresentam tricomas tectores com formato de candelabro (Fig. 1) e, em A. blitum, além de menores, as bractéolas apresentam tricomas glandulares (Fig. 2). 
O perigônio em pré-antese de $A$. tenella é formado por cinco tépalas cuculadas e conadas parcialmente na base. Em A. blitum ocorrem três tépalas cuculadas e livres. As tépalas de A. tenella apresentam três nervuras, sendo a central de maior calibre (Fig. 3) e as de A. blitum possuem uma única nervura de grande porte (Fig. 4). Em ambas as espécies, as nervuras fazem saliência na face abaxial e apresentam feixes vasculares colaterais. Os feixes vasculares de $A$. tenella apresentam-se envolvidos parcial ou totalmente por fibras (Fig. 5). Na face floemática das duas espécies ocorrem células parenquimáticas com betalaína (Fig. 5 e 6), mas estas células em A. blitum, tanto no perigônio como nas bractéolas, são amplas e têm disposição bisseriada e radial ao redor do floema (Fig. 6). As tépalas (Fig. 5) de A. tenella apresentam epiderme na face adaxial unisseriada com células alongadas e estreitas, de paredes delgadas, que sofrem colapso muito cedo expondo a hipoderme fibrosa, cujas células apresentam paredes espessas lignificadas e monocristais de oxalato de cálcio. Esta hipoderme possui células de paredes menos espessadas na base da flor. O mesofilo é parenquimático e constituído de poucos estratos de células alongadas tangencialmente e de paredes delgadas. A epiderme na face abaxial apresenta células fibrosas de paredes espessas (Fig. 5), embora em determinadas regiões, como a basal, as paredes celulares podem ser delgadas. Nessa face da epiderme ocorrem estômatos e tricomas tectores pluricelulares que têm formato de candelabro (Fig. 1). As tépalas (Fig. 6 e 7) de A. blitum apresentam estrutura diferente quando comparadas com a da primeira espécie. Nelas não ocorre colapso da epiderme na face adaxial, há hipoderme não esclerificada com areia cristalina, o mesofilo e epiderme na face abaxial possuem células de paredes delgadas (Fig. 7), e não ocorrem tricomas com formato de candelabro, e sim tricomas glandulares pluricelulares e unisseriados com célula apical ampla, semelhantes aos observados nas bractéolas (Fig. 2).

O ovário em A. tenella é romboidal (Fig. 8) e em $A$. blitum é obovado (Fig. 9). A epiderme externa (Fig. 10 e 11) em ambas as espécies é unisseriada, glabra e apresenta estômatos. $\mathrm{O}$ formato das células epidérmicas é diferente nas espécies, variando de cuboides a alongadas tangencialmente na primeira e somente cuboides na segunda. Variação estrutural significativa ocorre no mesofilo das espécies. Alternanthera tenella possui mesofilo em geral com dois estratos celulares parenquimáticos com células de paredes finas, sendo que o estrato interno (Fig. 10) sofre espessamento parietal secundário na metade superior do ovário, ainda em pré-antese. As células deste estrato apresentam espessamento em $\mathrm{U}$ e conteúdo cristalífero com monocristais romboédricos, cúbicos ou de formato irregular de oxalato de cálcio. Amaranthus blitum apresenta mesofilo parenquimático mais espesso, esponjoso, com dois a cinco estratos de células; não ocorre nessa espécie camada subepidérmica com espessamento em $U$, embora esta camada apresente areia cristalina (Fig. 11). A epiderme interna também é unisseriada e glabra nas duas espécies (Fig. 10 e 11), com células mais alongadas em $A$. tenella e cuboides, vacuoladas e papilosas na região apical do ovário em A. blitum.

No fruto em desenvolvimento, o perigônio (Fig. $12 \mathrm{e}$ 13) das duas espécies mantém-se com a mesma estrutura das flores, exceto por apresentar compressão ou colapso de alguns tecidos, principalmente nas tépalas de $A$. tenella. $\mathrm{O}$ pericarpo de A. tenella (Fig. 12) possui a mesma estrutura do ovário; em fase mais adiantada de desenvolvimento, as diferentes regiões do pericarpo podem se apresentar com células mais comprimidas, em virtude do crescimento da semente. No caso de A. blitum, o pericarpo apresenta modificações significativas (Fig. 14), pois formam-se pequenas arestas na superfície externa, o mesocarpo se torna mais esponjoso e exocarpo e endocarpo podem apresentar células papilosas.

$\mathrm{O}$ perigônio no fruto maduro das espécies possui em geral estrutura semelhante ao existente na flor aberta. Em A. tenella, o perigônio (Fig. 15) possui epiderme na face adaxial colapsada em algumas regiões e em outras as células são íntegras com paredes relativamente espessas, hipoderme fibrosa com conteúdo cristalífero descontínua, mesofilo parenquimático com células comprimidas na região adaxial, epiderme na face abaxial esclerificada exceto no bordo, e vascularização por três feixes colaterais envolvidos completa ou parcialmente por fibras. Os tecidos do bordo ou ápice do perigônio colapsam (Fig. 15). O perigônio de A. blitum, semelhante ao do fruto em desenvolvimento (Fig. 13), apresenta epiderme de ambas as faces e mesofilo com células de paredes delgadas; na nervura central das tépalas podem ocorrer células com betalaína envolvendo o único feixe vascular.

O pericarpo maduro de A. tenella (Fig. 15) é quase todo colapsado ou com células comprimidas, com exceção do mesocarpo interno que apresenta células providas de espessamento parietal em U e conteúdo cristalífero, restrito à metade superior do fruto. $\mathrm{O}$ pericarpo maduro (Fig. 16) de A. blitum é irregular, com pequenas arestas, apresentando exocarpo unisseriado com células amplas, algumas papilosas, de paredes delgadas. O mesocarpo (Fig. 16) desta espécie é constituído de duas regiões, uma externa aerenquimática com dois ou três estratos celulares, e outra interna formada por um único estrato de células de paredes relativamente espessas e não lignificadas, com areia cristalina; o endocarpo é composto de um estrato de células alongadas, comprimidas, sendo colapsado em algumas regiões (Fig. 16).

\section{Semente em desenvolvimento}

As sementes de ambas as espécies se originam de óvulos campilótropos, bitegumentados, crassinucelados, com a micrópila sendo limitada apenas pelo tegumento interno (endóstoma) (Figs. 17 e 18). O tegumento externo do óvulo de A. tenella apresenta dois ou mais estratos celulares e o interno é bisseriado. Amaranthus blitum apresenta ambos 

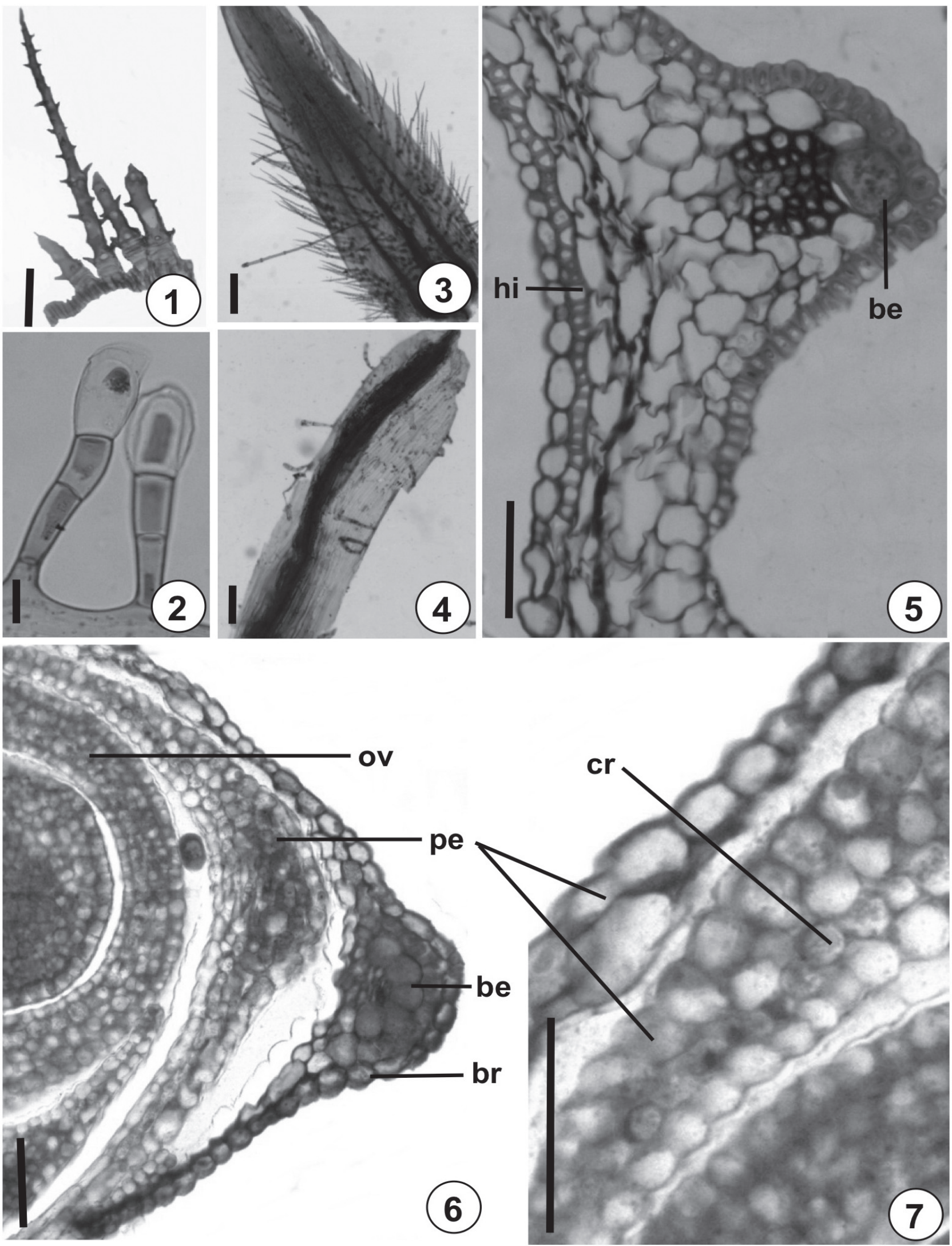

Figuras 1-7. Estrutura do perigônio e da bractéola de Alternanthera tenella Colla $(1,3,5)$ e de Amaranthus blitum Linnaeus $(2,4,6,7) .1,2$. Tricomas em detalhe das bractéolas. 3, 4. Tépalas diafanizadas. 5. Detalhe anatômico da tépala em seção transversal. 6, 7. Flor em seção transversal, mostrando detalhes do perigônio e bractéola. (be=célula com betalaína; br=bractéola; $c r=$ hipoderme com areia cristalina; hi=hipoderme; ov=ovário; pe=perigônio). Escalas = 50 $\mu \mathrm{m}(2,5,6,7), 100 \mu \mathrm{m}(1,3,4)$. 

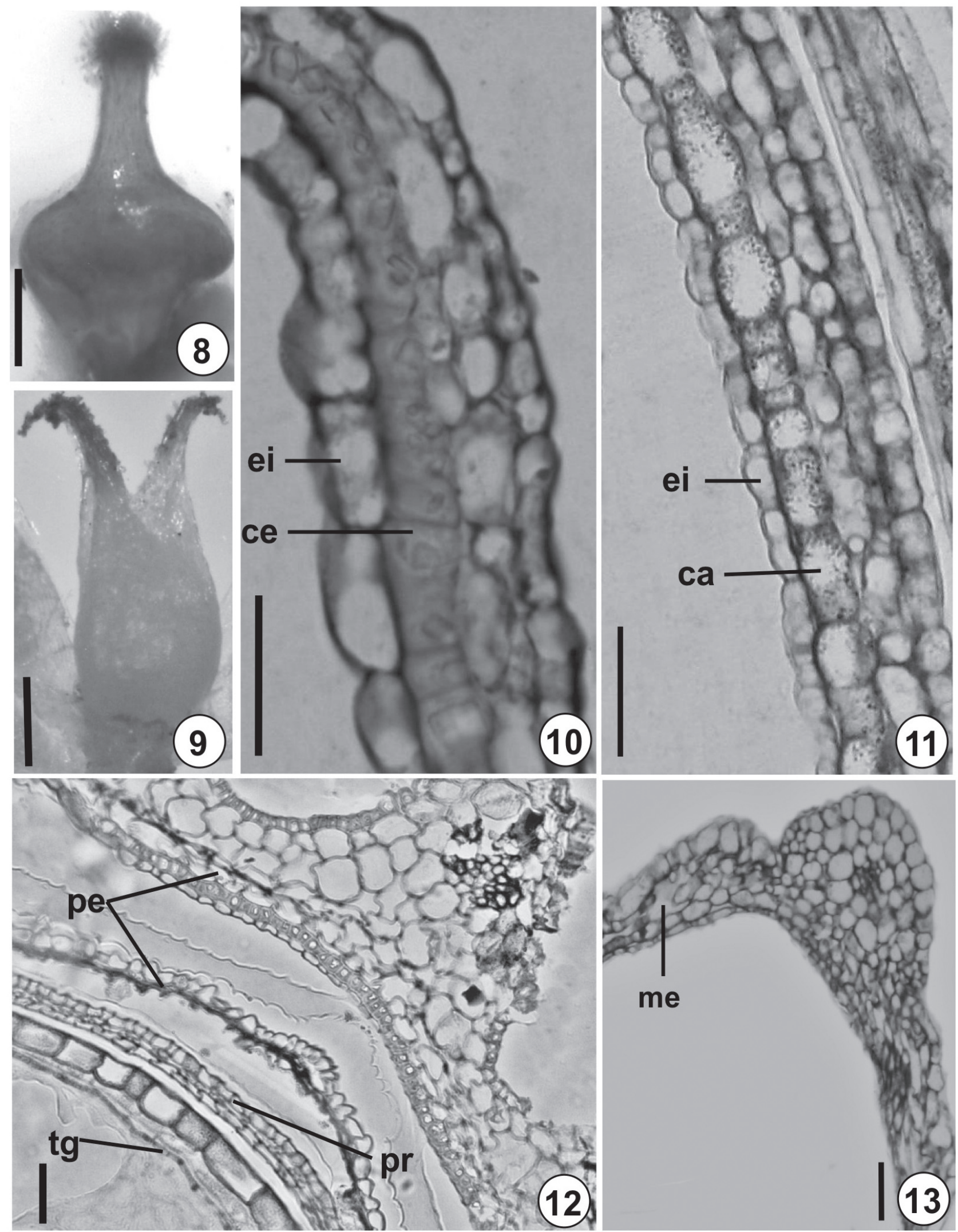

Figuras 8-13. Estrutura do ovário e perigônio do fruto jovem de Alternanthera tenella Colla $(8,10,12)$ e de Amaranthus blitum Linnaeus $(9,11,13) .8$, 9 . Vista geral do ovário. 10,11. Detalhe da parede do ovário em seção longitudinal. 12. Fruto jovem mostrando o perigônio, o pericarpo, e a semente com testa e tégmen, em seções transversais. 13. Perigônio do fruto jovem em seção transversal. (ca=camada celular com areia cristalina; ce=camada celular com espessamento em U; ei=epiderme interna; $\mathrm{me}=$ mesofilo esponjoso; pe=perigônio; pr=pericarpo; tg=tégmen). Escalas $=2 \mathrm{~mm}(8,9), 100 \mu \mathrm{m}(11,13), 50 \mu \mathrm{m}(10,12)$. 
os tegumentos bisseriados, exceto na região da micrópila que pode ter estrato adicional (Fig. 17 e 18).

Na semente em desenvolvimento de A. tenella (Fig. 12), a testa jovem, originada do tegumento externo do óvulo, apresenta a exotesta com células amplas de contorno quadrangular em seção transversal, com paredes relativamente espessas. A mesotesta ocorre em determinadas regiões do tegumento com células de paredes delgadas, e a endotesta é formada por células pouco alongadas e também com paredes delgadas. Em A. blitum (Fig. 19), a exotesta apresenta células cuboides, com paredes externas espessas, cujo espessamento se dispõe sob forma de estrias escuras que se projetam para o interior do lume celular; a endotesta é comprimida. O tégmen de ambas as espécies, de origem do tegumento interno do óvulo, apresenta colapso de uma das camadas do estrato bisseriado
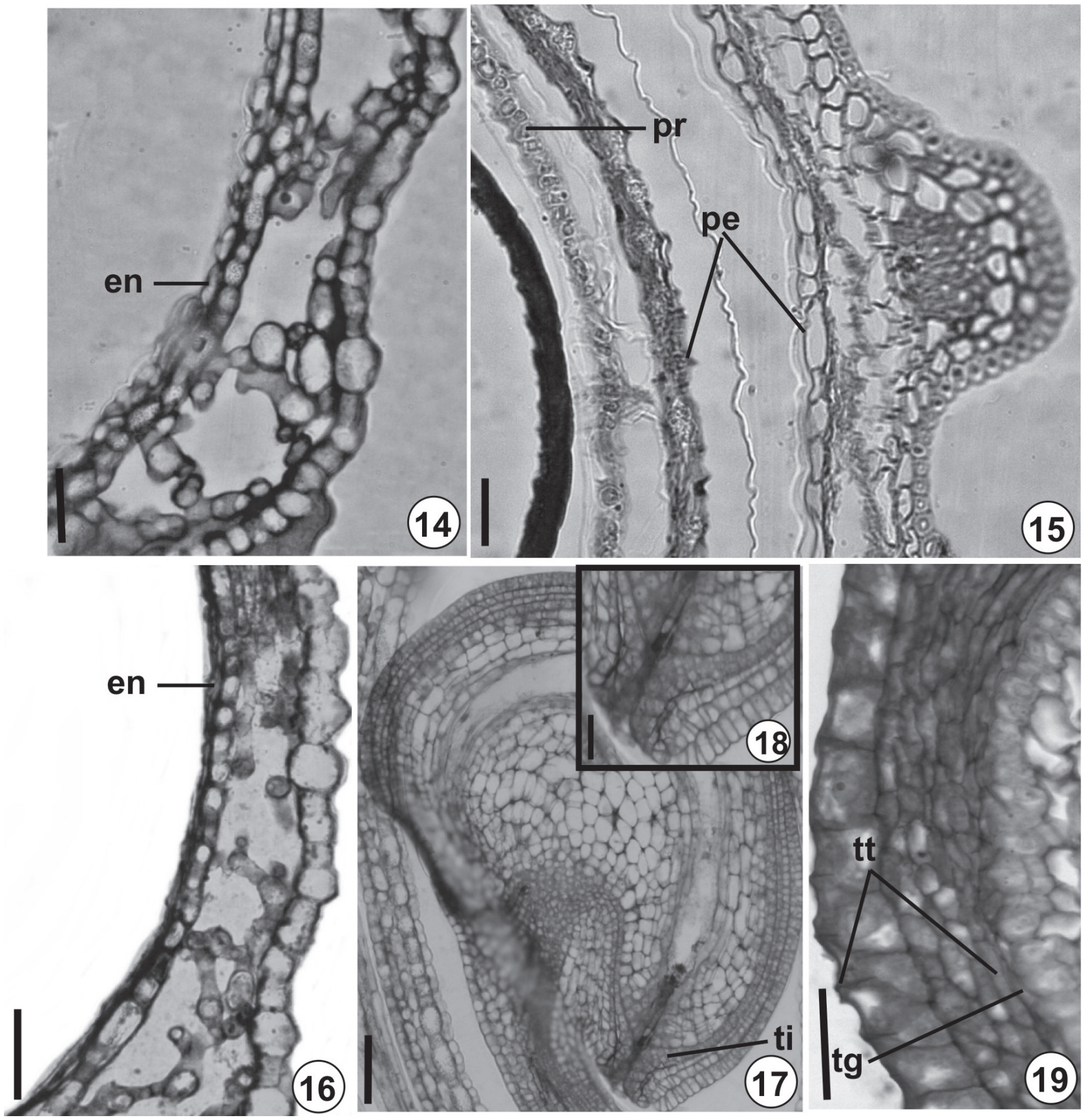

Figuras 14-19. Estrutura do fruto e óvulo de Alternanthera tenella Colla (15) e Amaranthus blitum Linnaeus (14-19). 14, 16. Pericarpo em desenvolvimento e maduro, em seções transversais. 15. Fruto maduro em seção transversal. 17, 18. Óvulo em seção longitudinal e detalhe da região micropilar. 19. Semente imatura em seção transversal, mostrando testa, tégmen e perisperma. (en=endocarpo; pe=perigônio; pr=pericarpo; tg=tégmen; ti=tegumento interno; $\mathrm{tt}=\mathrm{testa})$. Escalas = $50 \mu \mathrm{m}(14,15,16,17,19), 25 \mu \mathrm{m}(18)$. 
(Fig. 12 e 19); o estrato remanescente é formado por células vacuoladas, mais ou menos estreitas, de paredes delgadas em $A$. tenella e com espessamentos parietais secundários muito finos nas paredes radiais e internas de A. blitum. O nucelo mantém-se nessa fase de semente jovem, de natureza parenquimática, com células relativamente amplas de paredes delgadas (Fig. 19).

Ambas as espécies apresentam a semente madura de formato oblongo, de coloração marrom escura, de superfície lisa em A. tenella e porosa em A. blitum. A testa das duas espécies é representada principalmente pela exotesta, apresentando a mesotesta e a endotesta com células mais ou menos comprimidas ou colapsadas (Fig. 20 e 21). A exotesta (Fig. 20) em A. tenella é cuticularizada, com células alongadas tangencialmente ou mais curtas, com espessamento parietal secundário mais pronunciado na parede periclinal externa e nas paredes radiais; em determinadas regiões do tegumento todas as paredes podem se apresentar espessadas. A exotesta de A. blitum (Fig. 21) é composta de células cuboides a retangulares com parede periclinal externa espessa, em que o espessamento é estriado com projeções para o interior do lume. O tégmen das duas espécies é composto de um único estrato de células estreitas mais ou menos colapsadas (Fig. 20 e 21).

O embrião (Fig. 22 e 23) de ambas as espécies é curvo com eixo hipocótilo-radicular longo, plúmula representada por um conjunto reduzido de células meristemáticas (Fig. 24), sem diferenciação de primórdios foliares, e dois cotilédones de mesmo tamanho. Os cotilédones são dorsiventrais com um estrato de parênquima paliçádico e cerca de quatro camadas de parênquima esponjoso (Fig. 24 e 25). Nas sementes maduras das duas espécies ocorre perisperma reduzido (Fig. 21).

Os caracteres diferenciais relativos ao estudo comparativo dos frutos e estruturas não pericárpicas de A. blitum e A. tenella estão reunidos na Tab. 1.

\section{Discussão}

$\mathrm{O}$ fruto de $A$. tenella foi considerado como aquênio por apresentar características morfológicas, como fruto simples, seco indeiscente, unilocular, com uma única semente e, principalmente por derivar de ovário súpero. Spjut (1994) registrou que o fruto denominado cipsela ocorre em Asteraceae e se diferencia do aquênio por apresentar camada adicional (perianto) sobre o pericarpo, em razão de sua origem (ovário ínfero). Por outro lado, o autor menciona que muitos botânicos ignoram essa distinção e têm usado o termo aquênio. Spjut (1994) usou o termo cipsela para Amaranthaceae como fruto antocárpico simples por apresentar associado a ele partes acessórias da flor. A classificação do fruto de A. tenella como aquênio baseou-se em Marzinek et al. (2008) que fizeram extensa análise histórica e anatômica sobre aquênio e cipsela e concluíram que o primeiro é fruto simples originado de ovário súpero e o segundo é fruto complexo e resulta de ovário ínfero.

O enquadramento do fruto de A. blitum como utrículo e não como aquênio se deve aos caracteres morfoanatômicos, como ausência de tecido mecânico no pericarpo, pericarpo delgado com aspecto inflado. A caracterização como utrículo em Amaranthus também foi feita por Spjut (1994).

O perianto ou perigônio pode persistir no fruto maduro de espécies de várias famílias, dentre as quais Amaranthaceae (Roth 1977; Spjut 1994; Souza 2006; Oyama et al. 2010). Os frutos maduros de A. tenella e A. blitum possuem bractéolas e perigônio persistentes. É possível que as bractéolas e perigônio de A. tenella exerçam a função de proteção do fruto em desenvolvimento, pela presença de hipoderme esclerenquimática. A existência de tricomas tectores sob forma de candelabro em A. tenella e de tricomas glandulares em A. blitum pode auxiliar na dispersão do fruto, levando-se em conta que esta função foi sugerida por Judd et al. (2002) para frutos de Amaranthaceae que apresentam

Tabela 1. Caracteres potencialmente significativos na caracterização das espécies de Alternanthera tenella Colla e Amaranthus blitum Linnaeus.

\begin{tabular}{|c|c|c|}
\hline Caracteres & Alternanthera tenella & Amaranthus blitum \\
\hline Tipo de fruto & Aquênio, com superfície lisa & Utrículo, com superfície granulosa \\
\hline Bractéolas & Maiores, com tricomas tectores sob forma de candelabro; & Menores, com tricomas glandulares capitados \\
\hline Perigônio & Cinco tépalas cuculadas e conadas na base & Três tépalas cuculadas e livres \\
\hline Estrutura das tépalas & $\begin{array}{l}\text { Hipoderme fibrosa, de paredes espessadas e lignificadas com monocristais } \\
\text { de oxalato de cálcio; epiderme com tricomas em forma de candelabro }\end{array}$ & $\begin{array}{l}\text { Hipoderme não esclerificada, } \\
\text { com cristais de areia; epiderme } \\
\text { com tricomas glandulares capitados }\end{array}$ \\
\hline Vascularização do perigônio & Três nervuras, sendo a central de maior calibre & Uma única nervura de grande porte \\
\hline Formato do ovário & Romboidal & Obovado \\
\hline Mesofilo ovariano & $\begin{array}{l}\text { Dois estratos celulares, cujo estrato interno apresenta espessamento } \\
\text { em U e monocristais romboédricos, cúbicos ou irregulares }\end{array}$ & $\begin{array}{l}\text { Dois a cinco estratos de paredes delgadas e } \\
\text { camada subepidérmica com cristais de areia }\end{array}$ \\
\hline Pericarpo maduro & $\begin{array}{l}\text { Colapsado, com mesocarpo interno } \\
\text { com espessamento em U e monocristais }\end{array}$ & $\begin{array}{l}\text { Apenas endocarpo parcialmente colapsado; } \\
\text { com arestas e aerenquimático }\end{array}$ \\
\hline Semente madura & $\begin{array}{l}\text { Superfície lisa; exotesta com espessamento } \\
\text { nas paredes radiais e periclinal externa }\end{array}$ & $\begin{array}{l}\text { Superfície porosa; } \\
\text { exotesta com espessamento estriado }\end{array}$ \\
\hline
\end{tabular}




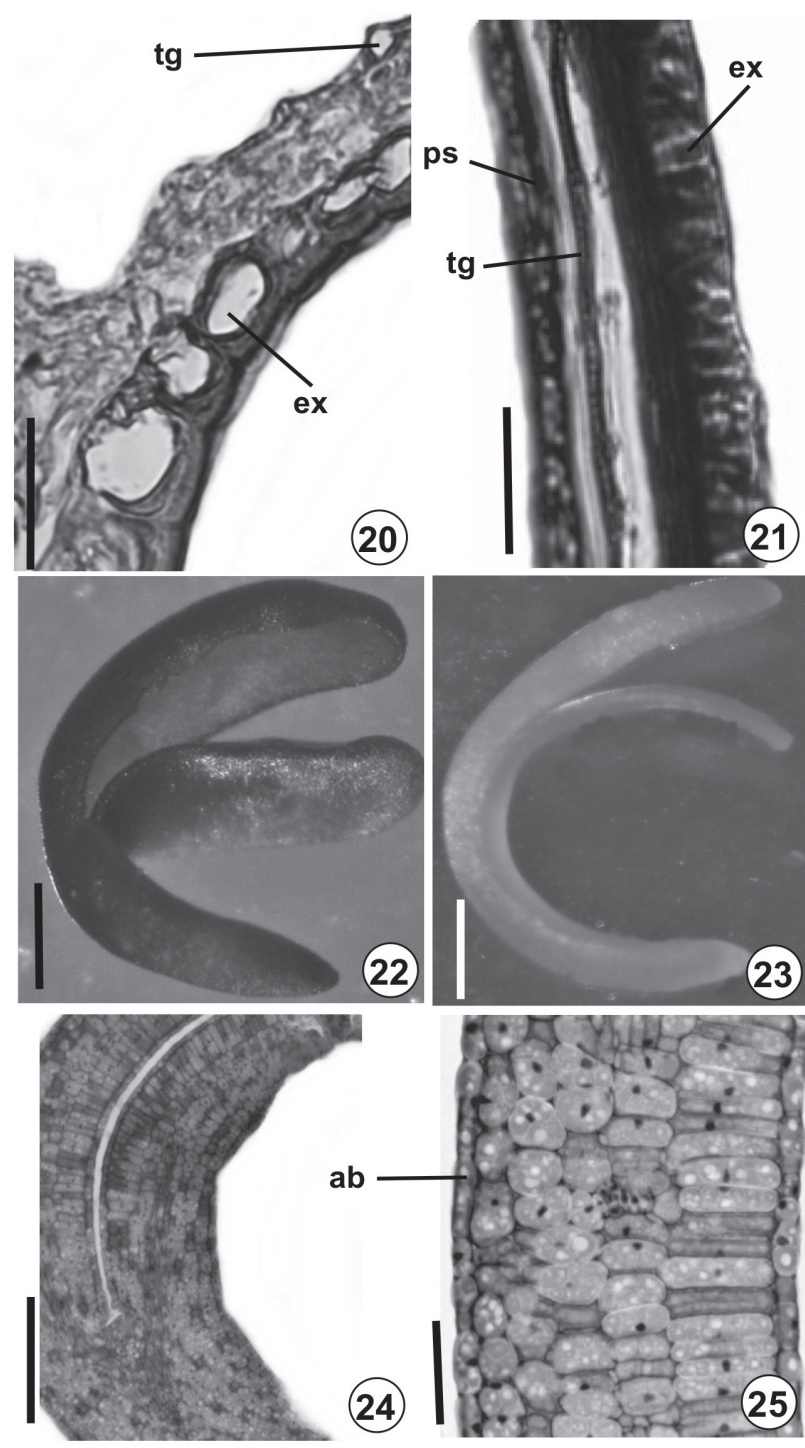

Figuras 20-25. Estrutura da semente madura de Alternanthera tenella Colla (20, 22, 24, 25) e Amaranthus blitum Linnaeus (21, 23). 20, 21. Envoltório da semente mostrando testa, tégmen e perisperma, em seções transversais. 22, 23. Aspecto geral do embrião. 24. Embrião em seção longitudinal. 25. Detalhe do cotilédone, em seção longitudinal. ( $a b=$ epiderme da face abaxial; ex=exotesta; ps=perisperma; tg=tégmen). Escalas $=25 \mathrm{~mm}(22,23), 30 \mu \mathrm{m}(20,21), 200 \mu \mathrm{m}$ (24), $50 \mu \mathrm{m}(25)$.

perianto piloso. É possível, também, que o perigônio de $A$. blitum realize função fotossintética, devido à presença de cloroplastos em células do mesofilo.

As bractéolas e o perigônio de A. tenella e A. blitum possuem betalaína, que é considerada um grupo químico complexo que se distingue das antocianinas por apresentar nitrogênio na molécula e por não responder às mudanças de pH como as antocianinas (Hopkins 1995). As betalaínas não ocorrem juntas na mesma planta e parecem desempenhar função na polinização das plantas e na proteção contra patógenos (Salisbury \& Ross 1992). Nas Caryophyllales, exceto Caryophyllaceae e Molluginaceae, os pigmentos de antocianina foram substituídos por betalaínas que têm assumido a função das antocianinas em tecidos vegetativos e reprodutivos (Soltis et al. 2005).

O perigônio de A. blitum se aproxima mais da estrutura das pétalas, segundo critérios estabelecidos por Fahn (1990), por não apresentar esclerênquima na nervura e por mostrar tecido vascular menos desenvolvido (uma única nervura). Por outro lado, o perigônio de A. tenella possui maior semelhança com o cálice (esclerênquima nas nervuras, hipoderme fibrosa e vascularização por três nervuras) que pode ter adotado a função de proteção (Roth 1977). A amarantácea Chamissoa altissima (Oyama et al. 2010) possui perigônio com estrutura semelhante ao de $A$. tenella, com hipoderme de células de paredes espessas e fibras ao redor do floema.

A diferenciação do ovário em fruto começa muito cedo nas espécies estudadas, especialmente em $A$. tenella, que já apresenta na flor aberta hipoderme esclerificada. Este fato é registrado para frutos de outras espécies por Roth (1977). Entretanto, o fruto de Chamissoa altissima, Amaranthaceae que também desenvolve hipoderme, a diferenciação deste tecido ocorre após a fertilização do ovário (Oyama et al. 2010). O fruto de A. blitum mantém-se de forma geral com estrutura semelhante à do ovário, diferente de outras espécies de Amaranthus que apresentam espessamento nas paredes das células do endocarpo (Costea et al. 2001).

Os óvulos e as sementes maduras de A. tenella e de A. blitum apresentam padrão estrutural básico de Amaranthaceae, conforme descrição de Corner (1976). Os caracteres básicos são óvulos bitegumentados e crassinucelados, e sementes bitegumentadas e exotestais, com perisperma e embrião curvo.

Werker (1997) registrou que a destruição de células do tegumento seminal pode ocorrer por absorção servindo como fonte de nutrientes para formação do endosperma, por colapso promovido pelo crescimento do endosperma e embrião ou por perda de água das células quando apresentam paredes delgadas. Em Amaranthaceae e Chenopodiaceae, o tegumento seminal é, em geral, reduzido à exotesta e ao endotégmen (Corner 1976). O estudo ontogênico de Amaranthus hypochondriacus mostrou que as células do tegumento interno e a epiderme interna da testa (endotesta) degeneram na semente madura (Pal et al. 1990). Por outro lado, na semente de Chamisssoa altissima persistem a testa e o endotégmen, degenerando apenas a camada externa do tegumento interno (Oyama et al. 2010). Nas sementes de A. tenella e A. blitum persiste a exotesta, e uma camada do tégmen mantém-se mais ou menos colapsada. Portanto, nas Amaranthaceae estudadas até o momento verifica-se que a exotesta é persistente, mas os outros estratos celulares da testa e do tégmen podem sofrer colapso dependendo da espécie considerada.

Em resumo, os resultados alcançados no presente trabalho mostraram, sob o ponto de vista morfoanatômico, que os frutos e as estruturas não pericárpicas persistentes de $A$. tenella e A. blitum apresentaram diferenças entre as duas espécies, ao contrário das sementes, que possuem caracteres muito semelhantes (Tab. 1). No caso das estruturas não pericárpicas (bractéolas e perigônio) e do fruto podem ser 
destacados caracteres que são potencialmente significativos na caracterização das espécies: os tipos diferentes de tricomas que ocorrem nas bractéolas e perigônio (tectores sob forma de candelabro em A. tenella e tricoma glandular em A. blitum); a vascularização das bractéolas (uma nervura em A. tenella e A. blitum) e perigônio (três nervuras em $A$. tenella e uma em $A$. blitum); hipoderme esclerenquimática cristalífera no perigônio de A. tenella e ausente em A. blitum; e a presença de mesocarpo com espessamento em $U$ e cristalífero em A. tenella e apenas cristalífero (areia cristalina) em A. blitum. A caracterização ontogênica estrutural dos frutos de ambas as espécies pôde confirmar que $A$. tenella apresenta fruto do tipo aquênio e A. blitum possui utrículo. Os caracteres estruturais das bractéolas e perigônio das duas espécies revelaram que essas folhas persistentes no fruto podem ter função ecológica importante no processo de proteção e dispersão de seus diásporos.

\section{Agradecimentos}

Os autores expressam agradecimentos ao $\mathrm{CNPq}$, por concessão de auxílio financeiro, e à Dra. Maria Salete Marchioretto, da Unisinos, Rio Grande do Sul, pela identificação das espécies.

\section{Referências bibliográficas}

Berlyn, G.P. \& Miksche, J.P. 1976. Botanical microtechnique and citochemistry. Ames, The Iowa State University Press.

Corner, E. J. H. 1976. The seeds of dicotyledons. Cambridge, Cambridge University Press.

Costa Silva, G.M.; Silva, H.; Almeida, M.V.A.; Cavalcanti, M.L.F. \& Martins, P.L. 2003. Morfologia do fruto, semente e plântula do mororó (ou pata de vaca) - Bauhinia forticata Linn. Revista de Biologia e Ciências da Terra 3(2): 1-15.

Costea, M.; Waines, G. \& Sanders, A. 2001. Structure of the pericarp in some Amaranthus L. (Amaranthaceae) species and its taxonomic significance. Aliso 20: 51-60.

Fahn, A. 1990. Plant anatomy. Oxford, Pergamon Press.

Foster, A.S. 1950. Techniques for the study of venation patterns in the leaves of angiosperms. Proceedings of the $7^{\text {th }}$ International Botanical Congress: 586-587.
Guerrits, P.O. 1991. The application of glycol methacrylate in histotechnology; some fundamental principles. Netherlands, University Groningen. Hopkins, W.G. 1995. Introduction to plant physiology. New York, John Wiley. Johansen, D.A.V. 1940. Plant microtechnique. New York, McGraw-Hill. Judd, S.W; Campel, S.C; Kellog, A.E; Stevens, F.P \& Donoghue, J. M. 2002. Plant systematics - a phylogenetic approach. Sunderlands, Sinauer Associates.

Leitão-Filho, H.F. 1968. Espécies de Amaranthus que ocorrem como invasoras no município de Campinas. Bragantia 27(36): 476-492.

Marzinek, J.; Paula, O.C. \& Oliveira, D.M.T. 2008. Cypcela or achene? Refining terminology by considering anatomical and historical factors. Revista Brasileira de Botânica 31(3): 549-553.

O’Brien, T.P.; Feder, N \& Mccully, M. E. 1964. Polychromatic staining of plant cell walls by toluidine blue O. Protoplasma 59: 368-373.

Oyama, S.O.; Souza, L.A.; Muneratto, J.C. \& Albiero, A.L.M. 2010. Morphological and anatomical features of the flower and fruit in developing of Chamissoa altissima (Jacq) Kunth (Amaranthaceae). Brazilian Archives of Biology and Technology 53(6): 1425-1432.

Pal, A.; Singh, R.P. \& Pal, M. 1990. Development and structure of seeds in Amaranthus hypochaondriacus $\mathrm{L}$. and its wild progenitor A. hybridus L. Phytomorphology 40: 145-150.

Paoli, A.A.S. 2006. Semente. Pp. 125-161. In: Souza, L.A. (Org.) Anatomia do Fruto e da Semente. Ponta Grossa, Editora Universidade Estadual de Ponta Grossa.

Prego, I.; Maldonado, S.; Otegui, M. 1998. Seed structure and localization of reserves in Chenopodium quinoa. Annals of Botany 82: 481-488.

Roth, I. 1977. Fruits of angiosperms. Pp. 122-128. In: Linsbauer, K.; Tischler, F.G. \& Pascher, A. (Eds.) Encyclopedia of Plant Anatomy. Berlin, Gebrüder Borntraeger.

Salisbury, F.B. \& Ross, C.W. 1992. Plant physiology. Belmont, Wadsworth Publishing Company.

Sass, J.E. 1951. Botanical microtechnique. Iowa, Iowa State College Press.

Shepherd, K.A.; Macfarlane, T.D. \& Colmer, T.D. 2005. Morphology, anatomy and histochemistry of Salicornioideae (Chenopodiaceae) fruits and seeds. Annals of Botany 95: 917-933.

Soltis, D.E.; Soltis, P.S.; Endress, P.K. \& Chase, M.W. 2005. Phylogeny and evolution of angiosperms. Sunderland, Sinauer Associates.

Souza, V.C. \& Lorenzi, H. 2008. Botânica Sistemática: Guia ilustrado para identificação de famílias de fanerógamas nativas e exóticas no Brasil, baseado em APG II. Seropédica, Instituto Plantarum.

Souza, L.A. 2006. Fruto. Pp. 10-123. In: Souza, L.A. (Org.) Anatomia do fruto e da semente. Ponta Grossa, Editora Universidade Estadual de Ponta Grossa.

Souza, L.A.; Rosa, S.M.; Moscheta, I.S.; Mourão, K.S.M.; Rodella, R.A.; Rocha, D.C. \& Lolis, M.I.G.A. 2005. Morfologia e anatomia vegetal - técnicas e práticas. Ponta Grossa, Editora Universidade Estadual de Ponta Grossa.

Spjut, R.W. 1994. A systematic treatment of fruit types. Memoirs New York Botanical Garden 70: 1-182.

Werker, E. 1997. Seed anatomy. Berlin, Gebrüder Borntraeger. 